Artigo original

Hegemonia - Revista Eletrônica do Programa de Mestrado em Direitos Humanos, Cidadania e Violência/Ciência Política do Centro Universitário Unieuro

ISSN: 1809-1261

UNIEURO, Brasília, número 24, Julho a Dezembro de 2018, pp. 5-23.

Recebido em: 18/2/2018

Avaliado em: 23/4/2018

Aprovado em: 13/5/2018

\title{
CONSIDERAÇÕES TEÓRICAS SOBRE OS FUNDAMENTOS DO GOVERNO REPRESENTATIVO
}

Deywisson Ronaldo Oliveira de Souza ${ }^{1}$ e Marcos Aurélio Guedes De Oliveira²

RESUMO: Dada a importância dos esquemas de representação política para as experiências democráticas contemporâneas, esse trabalho aborda alguns fundamentos sobre os quais se estrutura o pensamento do governo representativo na teoria política. Com base nas obras dos autores Federalistas, de Robert Dahl, Stuart Mill, Tocqueville e Bernard Manin, tecemos considerações acerca de elementos conflitantes, semelhantes e complementares que evoluíram e estão presentes nos sistemas políticos de diversos Estados. Longe de querer apontar a concretização desse debate em casos reais essa tentativa faz uma análise em torno da contribuição desses autores para os esquemas contemporâneos de representação política.

PALAVRAS-CHAVE: governo representativo; federalistas; Stuart Mill; Tocqueville; Dahl; Bernard Manin.

\footnotetext{
${ }^{1}$ Professor Substituto de Teoria Política na Universidade Federal de Pernambuco (UFPE) e Doutorando em Ciência Política na mesma instituição.

2 Professor Titular no Departamento de Ciência Política na UFPE e PhD em Government pela University of Essex.
} 
Artigo original

Hegemonia - Revista Eletrônica do Programa de Mestrado em Direitos Humanos, Cidadania e Violência/Ciência Política do Centro Universitário Unieuro

ISSN: 1809-1261

UNIEURO, Brasília, número 24, Julho a Dezembro de 2018, pp. 5-23.

ABSTRACT: Given the importance of political representation for contemporary democratic forms, this paper addresses some of the foundations on which representative government thinking is structured in political theory. Based on the works of the Federalist authors of Robert Dahl, Stuart Mill, Tocqueville, and Bernard Manin, we make considerations about conflicting, similar and complementary elements that evolve and are present empirically in the political systems of several States. Far from wanting to point out a concretization of the debate in real cases this attempt offers a debate around the response of these authors for the contemporary schemes of political representation. KEYWORDS: representative government; federalists; Stuart Mill; Tocqueville; Dahl; Bernard Manin.

\section{Introdução}

Da crítica feita à democracia direta como meio de assegurar a soberania do povo nos processos de tomada de decisões públicas é que surge a defesa da democracia representativa como instrumento condutor dos interesses individuais até as ações políticas. Os processos de tomada de decisões públicas assentados na participação direta dos indivíduos tal como acontecia nos esquemas institucionais da Grécia e da Roma antiga ou mesmo como defendido por Rousseau, se mostraram inapropriados para as necessidades das complexas associações políticas modernas. Nesse diapasão, a participação direta do cidadão na deliberação dos assuntos públicos deixou de ser o elemento definidor do estado democrático moderno. Suas novas demandas o deixavam em uma situação de impotência frente às exigências que um modelo de democracia participativa requer.

Contrariamente a Rousseau que enxergava na participação direta dos indivíduos um meio de evitar que grupos organizados sobrepusessem suas vontades particulares aos desejos gerais da comunidade (PATEMAN, 1992), Montesquieu e os autores Federalistas viam nas disposições oferecidas pelos governos de democracia direta os males que ameaçavam os interesses comunitários. Dessa maneira, a República como governo representativo na obra dos Federalistas concedia ao próprio sistema político os dispositivos que limitavam o surgimento de grupos com interesses divergentes dos da sociedade em geral. 
Artigo original

Hegemonia - Revista Eletrônica do Programa de Mestrado em Direitos Humanos, Cidadania e Violência/Ciência Política do Centro Universitário Unieuro

ISSN: 1809-1261

UNIEURO, Brasília, número 24, Julho a Dezembro de 2018, pp. 5-23.

Esses dispositivos oferecidos pelos Federalistas favoreciam a fiscalização mútua dos poderes constituintes e a responsividade dos eleitos para com os eleitores. Ao mesmo tempo em que o modelo de governo representativo proposto pelos Federalistas favorecia a igualdade política e a soberania popular, ele legitimava a democracia moderna sobre os fundamentos da representação política.

Dada a importância dos esquemas de representação política para as experiências democráticas contemporâneas, esse trabalho pretende abordar alguns fundamentos sobre os quais se estrutura o pensamento do governo representativo na teoria política. Abordando as obras dos autores Federalistas, de Robert Dahl, Stuart Mill, Tocqueville e Bernard Manin, tecemos algumas considerações acerca de elementos conflitantes, semelhantes e complementares que evoluíram e estão presentes empiricamente nos sistemas políticos de diversos Estados. Longe de querer apontar a concretização desse debate em casos reais - o que demandaria um esforço investigativo especial - essa tentativa oferece uma análise em torno da contribuição desses autores para os esquemas contemporâneos de representação política. Para isso, Manin (1997;1995) será útil à medida em que permite a visualização da evolução da democracia representativa até a contemporaneidade.

O trabalho segue uma lógica na qual primeiramente fazemos essa breve introdução, cujo objetivo não ultrapassa o intuito de clarear nossas intenções e permitir que as diretrizes que guiam nossa tentativa se tornem evidentes. Na seção seguinte, passamos a levantar o argumento dos autores abordados e pensar nas exigências que os sistemas políticos requerem dos modelos de representação política. Na seção 3 oferecermos ao leitor a sequência histórica construída por Manin (1997;1995), que permite enxergar o reflexo desse debate nas experiências de democracia representativa. Por fim, tecemos algumas considerações finais, onde é possível confirmar a importância dos esquemas de representação política para a legitimidade dos governos democráticos fundados nos ideais de soberania popular e igualdade política. 
Artigo original

Hegemonia - Revista Eletrônica do Programa de Mestrado em Direitos Humanos, Cidadania e Violência/Ciência Política do Centro Universitário Unieuro

ISSN: 1809-1261

UNIEURO, Brasília, número 24, Julho a Dezembro de 2018, pp. 5-23.

2. Pensando os fundamentos estruturadores do governo representativo moderno

Os Autores Federalistas

A estratégia de iniciar a exposição de alguns dos fundamentos estruturantes do pensamento moderno sobre representação política pelos escritos canônicos dos autores federalistas nos auxilia na medida em que eles fornecem o insumo teórico necessário para se pensar o governo representativo como alternativa a experiência democrática direta. Nesse sentido passaremos a abordar as suas principais ideias salientando sempre que possível a importância dos esquemas de representação política para o arranjo institucional por eles defendidos.

Os artigos federalistas foram redigidos dentro de um contexto histórico especifico cuja finalidade de seus autores era a de convencer o povo da província de Nova Iorque a aceitar a nova Constituição dos Estados Unidos (EUA), proveniente da Convenção de Filadélfia de 1786. Os seus 85 capítulos são o resultado de um processo histórico que se iniciou com as discordâncias entre colonos e ingleses sobre as taxas de tarifação comercial entre a metrópole e a colônia e que culminou na Guerra de Independência do EUA. O argumento dos seus autores -John Jay, Alexander Hamilton e James Madison - se centrava na contraposição de uma engenharia institucional federalista frente à Confederação de estados em que a União das 13 colônias até então vivia. Os autores federalistas argumentavam em torno das salvaguardas que um governo republicano podia oferecer ao povo, sobretudo frente aos perigos que os governos de democracia direta ofereciam. Ademais, os federalistas temiam os danos que as deficiências resultantes de uma representação política deficiente e também aquelas males que a extrapolação dos limites e das funções dos poderes constituintes podiam trazer.

Diante das incapacidades institucionais que a Confederação enfrentava para propor um ambiente de prosperidade política, os autores saíram em defesa de um novo desenho institucional mais eficiente e que eliminasse os danos que um governo com princípios republicanos distorcidos representava. Nesse sentido a defesa de uma nova Constituição que abarcasse os verdadeiros princípios republicanos é o tema recorrente em toda a obra. Uma nova Constituição significava a 
Artigo original

Hegemonia - Revista Eletrônica do Programa de Mestrado em Direitos Humanos, Cidadania e Violência/Ciência Política do Centro Universitário Unieuro

ISSN: 1809-1261

UNIEURO, Brasília, número 24, Julho a Dezembro de 2018, pp. 5-23.

instauração de uma nova engenharia institucional que expurgasse as deficiências que o governo fragmentado das 13 províncias estava propiciando.

Essa nova estrutura institucional pretendia reformular as instituições desse governo republicano e para isso os autores deram um novo significado ao termo República, reaproveitando aquilo que a história podia oferecer a essa nova experiência de governo democrático.

Dentre essas instituições republicanas que foram aperfeiçoadas ao longo do tempo e que constituem vantagens ao diminuir as imperfeições da democracia, têm lugar de destaque: 1) a divisão e a distribuição dos poderes entre o Legislativo, o Executivo e o Judiciário; 2) a representatividade do povo na legislatura. Outras mudanças que os federalistas propuseram fizeram com que se caminhasse em torno de adequações institucionais que pudessem promover um ambiente político mais estável e centralizado, que limitasse os desejos de grupos facciosos e que pudesse tirar do povo a melhor forma de representação política. Nesse mesmo sentido, os autores trazem para o debate a importância da estabilidade dos juízes, que se tornam inamovíveis, como também a instituição da representação popular por meio de deputados escolhidos pelo povo. Para os federalistas essas medidas fortaleciam as estratégias de independência dos poderes e a fiscalização entre eles.

O caráter misto dessa nova Constituição funcionava como uma estratégia do próprio sistema de freios e contrapesos proposto pelos federalistas. Ela criava uma dupla representação na legislatura e reforçava ainda mais a fiscalização pelo povo. $O$ bicameralismo pretendia aglomerar simultaneamente tanto os anseios do povo, por meio da representação na Câmara dos Deputados, quanto a vontade de toda a nação, por meio da representação igualitária das províncias no Senado.

Ao definir as facções como o agrupamento de cidadãos que ao formarem uma minoria ou uma maioria estão intencionados a estabelecer um governo com interesses divergentes daqueles constantes na sociedade, fica claro a importância do desenho institucional defendido pelos federalistas para a sobrevivência da união dos 13 estados. Partindo da perspectiva de que prevenir as causas do surgimento de grupos facciosos é uma ilusão, para os federalistas o que restava fazer era aplicar os devidos remédios, ou seja, corrigir os efeitos que essas facções pudessem causar. Dessa forma, os autores afirmam que se essas facções não incorporassem a maioria da sociedade, o remédio a 
Artigo original

Hegemonia - Revista Eletrônica do Programa de Mestrado em Direitos Humanos, Cidadania e Violência/Ciência Política do Centro Universitário Unieuro

ISSN: 1809-1261

UNIEURO, Brasília, número 24, Julho a Dezembro de 2018, pp. 5-23.

disposição seria destruir, por meio de votação, os projetos prejudiciais que esse grupo engendrava. Desse fato podemos extrair a importância da escolha dos representantes pelo povo para a estabilidade e preservação da União. Já quando se tratasse do surgimento de grupos facciosos que aglomerassem a maior parcela da sociedade, os autores concluem que o remédio seria inibir o desenvolvimento de paixões e interesses comuns.

No que se refere à escolha dos representantes pelo povo, os artigos federalistas evidenciam que as democracias diretas pelo fato de serem menores e terem contingente de cidadãos mais reduzido naturalmente favorecem a comunidade de interesses na sociedade. Ao passo que a heterogeneidade de interesses nos governos em grandes extensões territoriais atua como um impedimento natural às paixões geradoras de grupos facciosos.

Quanto a escolha dos melhores representantes o contingente de cidadãos possibilitaria que proporcionalmente pudessem ser escolhidos os melhores e mais preparados, como também dificultaria a eleição daqueles candidatos sem merecimentos. Para evitar o risco de representantes com interesses muito particulares e dependentes daqueles que os elegem, os autores federalistas sugerem que os interesses locais fiquem atrelados a legislatura dos estados e que na legislatura nacional fiquem resguardados apenas os interesses da nação. Sendo assim não podemos tirar de mente que a instituição do governo representativo na obra dos federalistas se configura como mais um dos mecanismos de fiscalização disponíveis e que faz oposição à democracia direta e aos perigos que eles nela identificaram.

\section{Robert Dabl}

Já Robert Dahl, no Prefácio à Teoria da Democracia, elabora um argumento crítico a concepção federalista de que a ausência de freios incentivaria a existência de um governo tirânico que limitaria os direitos dos indivíduos. O julgamento de Dahl (1989) se concentra em torno de duas concepções distintas de democracia, a madisoniana, central no pensamento federalista, e outra populista que retira suas alegações da soberania popular e da igualdade política. Na concepção federalista, essa 
Artigo original

Hegemonia - Revista Eletrônica do Programa de Mestrado em Direitos Humanos, Cidadania e Violência/Ciência Política do Centro Universitário Unieuro

ISSN: 1809-1261

UNIEURO, Brasília, número 24, Julho a Dezembro de 2018, pp. 5-23.

ausência de controles externos impulsionaria os indivíduos detentores de poder a limitar os direitos de outros indivíduos, desta forma, criando-se um ambiente de tirania (DAHL, 1989, p. 14). De modo igual, a concentração dos poderes - Legislativo, Executivo e Judiciário - em mãos únicas levaria a um governo tirânico.

Para Robert Dahl, o argumento madisoniano falha ao não delimitar quais seriam os direitos naturais cerceados que criariam uma condição análoga a de tirania. Apesar de conectar os pressupostos da "privação dos direitos naturais" com os da "concentração de poderes", e disso deduzir o desenvolvimento do governo tirânico, Dahl (1989) condena a debilidade dos argumentos federalistas por carecerem de elementos que demonstrem como tal concentração de poderes gera esse sistema de privação de direitos.

A concepção federalista de democracia ou madisoniana, como o próprio Dahl preferiu chamar, retira seu segundo argumento da percepção de que devem existir controles para os males que as facções podem causar na sociedade. A crítica dablsiana apela para o fato de que Madison não fornece condições para se pensar como os processos de derrubada dos interesses dos grupos minoritários facciosos ocorreriam em uma sociedade onde prevalecesse a vontade da maioria. Para Dahl (1989), as afirmações dos federalistas não passavam de idealizações com aplicabilidade duvidosa. A capacidade de a República funcionar como barreira para o desenvolvimento de paixões que concentrassem interesses idênticos na maioria dos indivíduos representou para Dahl um argumento empiricamente deficiente.

A segunda concepção de democracia combatida por Dahl (ibid.) é aquela que se justifica na consecução da vontade da maioria e na atribuição do mesmo valor as vontades de todos os indivíduos. A crítica de Dahl (1989) se concentra em torno das ideias que estruturam a soberania popular e a igualdade política e são distribuídas em três eixos: (i) um técnico, que coloca em cheque a legitimidade das escolhas da maioria como sendo as mais democráticas; (ii) um ético, que se insere na discussão das preferências da soberania absoluta e da igualdade política, ao invés da soberania limitada; e o iii) eixo empírico aborda o caráter tirânico e a possibilidade de sobrevivência de um sistema onde a regra da maioria concede a uma minoria de representantes o poder ilimitado de governo. Robert Dahl ainda 
Artigo original

Hegemonia - Revista Eletrônica do Programa de Mestrado em Direitos Humanos, Cidadania e Violência/Ciência Política do Centro Universitário Unieuro

ISSN: 1809-1261

UNIEURO, Brasília, número 24, Julho a Dezembro de 2018, pp. 5-23.

coloca em discussão quais devem ser os critérios utilizados para escolher aqueles indivíduos que estarão aptos a votar.

Ao enfrentar essa problemática conflitante entre os aspectos normativos e teóricos da democracia com os aspectos empíricos presentes na realidade dos sistemas de governos que convergem regras majoritárias da soberania popular, dos arranjos da engenharia institucional com os esquemas práticos da igualdade política defendidos pelos federalistas, Dahl (1989) elabora a poliarquia como sua concepção de democracia. Para ele a democracia real deveria conceder os requisitos essenciais sobre os quais se construiria um esquema ideal necessário à maximização da experiência poliárquica.

$\mathrm{Na}$ estrutura de democracia poliárquica de Dahl (ibid.) as eleições têm papel de destaque. Embora não sejam suficientes para que se chegue à poliorquia, elas aprimoram a experiência democrática ao incluir os anseios dos grupos minoritários. Dada a importância da inclusão das diversas minorias para o estabelecimento da poliarquia, o autor elaborou algumas condições essenciais para o cumprimento dessa regra e a maximização do governo democrático, são elas: 1) os indivíduos votam de acordo com suas preferências; 2) o voto dos cidadãos tem o mesmo peso; 3) vence aquele que conseguir o maior número de votos; 4) a opção de incluir uma nova alternativa caso ela não esteja incluída na disputa; 5) os indivíduos devem ter as mesmas informações sobre as alternativas oferecidas; 6) as alternativas que receberem mais votos tem preferência sobre àquelas que receberam menos votos; 7) as diretrizes dos eleitos devem ser executadas; e 8) que as decisões tomadas durante as eleições estejam subordinadas pelas sete condições anteriores.

Tais condições assentam-se sobre os princípios da soberania popular e da igualdade política e propõem um governo democrático representativo onde a pluralidade dos grupos sociais prevalece. Embora se concentre em construir um argumento crítico frente aos pressupostos federalistas e populista de democracia, é notável a contribuição dablsiana ao pensamento político de representação ao viabilizar um quadro de requisitos essenciais sobre o qual a democracia pluralista se estrutura. Ao unificar as preposições teóricas que reafirmavam a soberania do povo e a igualdade política e transformá-las em um esquema empírico aplicável, Dahl (1989) criou uma plataforma comparativa em 
Artigo original

Hegemonia - Revista Eletrônica do Programa de Mestrado em Direitos Humanos, Cidadania e Violência/Ciência Política do Centro Universitário Unieuro

ISSN: 1809-1261

UNIEURO, Brasília, número 24, Julho a Dezembro de 2018, pp. 5-23.

que experiências democráticas podem se moldar e maximizar a participação dos diversos grupos sociais nos esquemas de deliberação pública.

\section{Stuart Mill}

Acreditamos que não haveria ponto de partida mais adequado para inserimos a abordagem sobre os fundamentos do governo representativo em Stuart Mill do que o questionamento por ele feito sobre a possibilidade das formas de governo serem uma questão de escolha. Certamente que o desejo dele ao fazer essa pergunta aos seus leitores tenha sido o de fazê-los pensar na perspectiva do governo representativo como um sistema de deliberação pública aprimorado, no qual as sociedades intelectualmente mais desenvolvidas tenderiam a chegar. Isso pois a concepção milliana de democracia se funda na percepção de que os pressupostos morais têm mais valor, o que invariavelmente guia os indivíduos para escolhas que beneficiam a comunidade.

Sendo os indivíduos agentes civicamente aprimorados, que em detrimento do ganho individualista inclinam-se para a ação direcionada ao bem da comunidade, fica perceptível na obra do pensador inglês a tendência socialmente construída do homem em fomentar e legitimar as decisões e as instituições políticas mais aprimoradas. É nesse sentido que Mill (1981) instaura a essência da retroalimentação entre o progresso social e participação cívica, tema que foi posteriormente abordado por Alexis de Tocqueville.

No que se refere a forma de governo, a concepção milliana de democracia representativa está inserida no contexto de alimentação mútua entre aprimoramento social e participação popular. Ao permitir simultaneamente o aperfeiçoamento dos indivíduos e o seu autogoverno, o modelo representativo de Mill (1981) cria uma tríade de soberania popular, aperfeiçoamento do homem e o progresso social.

Essa complementaridade teórica que Stuart Mill nos oferece entre o autogoverno do povo, o desenvolvimento das capacidades individuais e a expansão das condições sociais que sustentam a democracia representativa fortalece a percepção acerca da representação política como melhor forma 
Artigo original

Hegemonia - Revista Eletrônica do Programa de Mestrado em Direitos Humanos, Cidadania e Violência/Ciência Política do Centro Universitário Unieuro

ISSN: 1809-1261

UNIEURO, Brasília, número 24, Julho a Dezembro de 2018, pp. 5-23.

de governo. Isso porque ela traria mais benefícios para o corpo social. Fator esse que certamente concede a esse pensamento um lugar de destaque na tradição moderna da teoria política.

\section{Alexis de Tocqueville}

A intenção de Tocqueville era influenciar o comportamento dos homens e reverter os processos de perda de interesse nas atividades públicas. Para Jasmim (2005, p. 37), a sua obra transcendeu as contingencias locais e os objetivos de simplesmente responder aos problemas políticos do seu tempo alcançando assim uma universalidade teórica. Sua viagem aos Estados Unidos lhe permitiu enxergar a intrínseca relação que existia no sistema político americano entre educação e cultura e seus efeitos na manutenção da soberania popular. O pensador francês foi surpreendido pela capacidade geradora de incentivos ao desenvolvimento pessoal que as instituições políticas americanas fomentavam. A igualdade política como elemento essencial da cultura democrática norte-americana atuava juntamente as leis e as instituições políticas e sociais como elementos que reforçavam a soberania popular.

A educação, cultura, costumes e a religião nos Estados Unidos funcionavam para Tocqueville (1977) como forças que impulsionavam as suas instituições democráticas a incentivarem a participação popular e a soberania do povo. Nesse sentido a função da representação política ganha o sentido da transformação das vontades individuais em políticas públicas.

O dilema tocquevilliano da tensão entre igualdade e liberdade é seu sistema conceitual mais aprimorado (JASMIM, 2005). Para ele em uma sociedade igualitária e com liberdade política depende da práxis e de um conjunto de valores cujos pressupostos tendem e a ser solapados pelo desenvolvimento da própria democracia. Sendo a liberdade política corroída pelo desenvolvimento da democracia, a única saída possível para esse problema seria a efetiva participação dos cidadãos na esfera pública (ibid.; TOCQUEVILLE, 1977).

Objetivando traçar o caminho no qual a democracia e seu inerente processo de individualização das relações sociais solapa os elementos essenciais da liberdade política, Tocqueville 
Artigo original

Hegemonia - Revista Eletrônica do Programa de Mestrado em Direitos Humanos, Cidadania e Violência/Ciência Política do Centro Universitário Unieuro

ISSN: 1809-1261

UNIEURO, Brasília, número 24, Julho a Dezembro de 2018, pp. 5-23.

(ibid.), elabora esquemas de tensão entre democracia e aristocracia e entre liberdade e servidão. A dualidade entre aristocracia e democracia nos serve para entendermos o processo histórico no qual as sociedades hierárquicas ou sociedades feudais foram progressivamente sendo substituídas por sociedades com igualdade de condições sociais. Processo esse que ele compreende como sendo uma revolução irresistível da democracia.

Para entender o escopo conceitual de democracia em Tocqueville (1977), é necessário capturar os dois níveis distintos em que o autor se apoiou para destrinchá-la, (i) um histórico-empírico cujo objetivo era o de fazer alusão as sociedades que deixaram pra trás as estruturas hierarquizadas do feudalismo, e outro (ii) teórico, que se fundamenta em um sentido abstrato de ordem social fundada sobre a igualdade (JASMIM ,2005).

Para Tocqueville (1977), o conceito de aristocracia é caracterizado pelo seu caráter hierárquico e remete diretamente à experiência medieval europeia onde os indivíduos eram articulados uns aos outros, como em uma relação de senhor e servo. A legitimidade dessas relações servis se fundava no pensamento, nas mentalidades, e assim a desigualdade era legalizada e fundada como princípio. Jasmim (2005, p. 43), percebe que a própria desigualdade tornou-se a garantia da unidade das sociedades aristocráticas dentro do pensamento tocquevilliano.

O processo de saída da hierarquização social própria das sociedades aristocráticas e a chegada da sociedade igualitária, onde os indivíduos são independentes, configura aquilo que Tocqueville compreende como revolução democrática. Para Tocqueville (1977) essa igualização social não significava a eliminação de todo tipo de desigualdade existente na sociedade, mas aquelas que eram permanentes, que constituíam a ordem e eram passadas de pai pra filhos. A diferença estava na percepção de que nas sociedades aristocráticas as desigualdades eram permanentes, e nas democráticas, revogáveis.

Nesse sentido, os costumes desempenhavam um papel importante no que concerne a manutenção da ordem social. No caso do sistema político norte-americano os hábitos eram fator fundamental para manutenção da ordem social (TOCQUEVILLE, 1977, p. 232). Essa visão é reaplicada em um âmbito mais geral e abstrato onde o autor pôde tecer generalizações sobre a 
Artigo original

Hegemonia - Revista Eletrônica do Programa de Mestrado em Direitos Humanos, Cidadania e Violência/Ciência Política do Centro Universitário Unieuro

ISSN: 1809-1261

UNIEURO, Brasília, número 24, Julho a Dezembro de 2018, pp. 5-23.

efetividade dos costumes como garantias da coesão social e da ordem política. Isso porque para Tocqueville os costumes fornecem coesão à existência social, definem os padrões de normalidade e garantem a continuidade das leis (JASMIM, 2005, p. 46).

A contaminação das diversas esferas públicas e sociais pela democracia é visível na obra de Tocqueville. Pois, na medida em que os costumes democráticos são paulatinamente espalhados no espectro social, mais as suas esferas vão se contaminar e tornar-se mais igualitárias. Nesse sentido, vigora a percepção de que quanto mais consolidada é determinada instituição, mais se espera a continuidade das mudanças na direção em que elas estão acontecendo (JASMIM, 2005, p. 48).

A segunda dualidade que Tocqueville (1977) usa para mostrar como a igualdade política em governos democráticos acaba destruindo a liberdade política é aquela que acontece entre liberdade e servidão. A distinção entre liberdade e servidão se assenta na diferença entre um sistema político em que os homens governam a si mesmos e outro em que não participam das atividades públicas. $\mathrm{O}$ interessante aqui é que na concepção tocquevilliana o que defini a natureza do governo democrático não o conteúdo ou as medidas que o governo toma, e sim a participação popular na esfera pública. O autor assenta a distinção entre liberdade e servidão na percepção de que a pujança do envolvimento dos indivíduos nas atividades políticas e o envolvimento dos cidadãos na deliberação dos negócios públicos são as características que separam um povo livre de outro que vive em uma condição de dominação.

O objetivo de Tocqueville ao abordar essa distinção entre liberdade e servidão foi mostrar como a igualdade, uma disposição da própria democracia, faz com que a individualismo e a privatização das relações sociais tornem os indivíduos cada vez mais desinteressados pelo tratamento dos negócios públicos, instaurando uma relação de servidão com o próprio Estado. As consequências de uma nova sociedade estabelecida sobre os princípios da igualdade política eram os grandes males que Tocqueville temia. A instabilidade social como traço marcante dessas sociedades democráticas contribua para a apatia política, pois os homens só pensariam em cultivar suas riquezas e perseguir a manutenção de seus status. O resultado dessas novas configurações sociais era mediocridade cultural e alienação cívica. 
Artigo original

Hegemonia - Revista Eletrônica do Programa de Mestrado em Direitos Humanos, Cidadania e Violência/Ciência Política do Centro Universitário Unieuro

ISSN: 1809-1261

UNIEURO, Brasília, número 24, Julho a Dezembro de 2018, pp. 5-23.

O caráter do modelo de representação política em Tocqueville também é contaminado por essa negatividade que permeia sua obra no que se refere aos danos que a apatia política favorece. Para ele, quanto mais os indivíduos delegam aos representantes o poder para decidir a vida pública, mais eles se restringem aos seus interesses privados e se igualam aos súditos no Leviatã (JASMIM, 2005).

3. Ponderações sobre o reflexo do pensamento de representação política nos modelos de democracia representativa

A rica obra de Alexis de Tocqueville permite-nos apreender um conjunto de suposições acerca dos perigos que a democracia como governo representativo pode oferecer, sobretudo aqueles que fazem referência a apatia política e a tirania da maioria. Sua contribuição para o pensamento moderno sobre o governo representativo advém do conflito que ele mesmo formulou entre a representação política em democracias e em aristocracias: uma evolução da função representativa que deixou de exercer um papel de auto representação para a configuração de esquemas de representação popular.

O problema que Tocqueville identifica no âmbito dos governos democráticos se transforma no seu sistema conceitual mais importante e faz-nos pensar nos limites do governo representativo. Essa degradação da capacidade cívica dos indivíduos também foi alertada por Mill (1981), mas foi remediada quando ele adverte para que o sistema de governo fomente a participação cidadã nas esferas públicas de deliberação. Percebemos ai uma divergência teórica entre esses dois pensadores no que se refere às consequências do sistema político para a capacidade cívica dos indivíduos. Enquanto o governo representativo em Mill incentivava o aprimoramento intelectual e a deliberação do povo nos negócios públicos, em Tocqueville ele induzia a degradação intelectual, ao desinteresse pelas atividades públicas.

A obra de Tocqueville (1977) ainda nos permite pensar na necessidade de mecanismos institucionais que limitem os desejos prejudiciais das grandes maiorias frente aos direitos dos grupos 
Artigo original

Hegemonia - Revista Eletrônica do Programa de Mestrado em Direitos Humanos, Cidadania e Violência/Ciência Política do Centro Universitário Unieuro

ISSN: 1809-1261

UNIEURO, Brasília, número 24, Julho a Dezembro de 2018, pp. 5-23.

minoritários, assim como Mill (1981) preconizou. Na concepção milliana, a necessidade de existência de mecanismos institucionais que habilitassem as minorias a frear os desejos prejudiciais das grandes maiorias funcionava como um remédio frente àquelas possíveis deficiências de um governo representativo.

No esquema teórico poliárquico de Dahl (1989), a importância da inclusão das minorias concedia a instituição eleitoral, e seu esquema de condições essenciais para a instauração do governo de soberania popular, o seu maior destaque. Enquanto as eleições em Dahl (ibid.) Mill (1981) e no pensamento dos autores federalistas respectivamente desempenhavam um papel de incluir as minorias, favorecer o aprimoramento dos cidadãos e servir como um controle externo, em Tocqueville (1977) elas incentivavam a ilusão de que os homens governavam a si mesmos, atuando como um meio de atenuar o caráter despótico do governo representativo. Ademais, percebemos um ponto de confluência teórica entre as obras já mencionadas de Dahl e Tocqueville quando convergem para um sistema político não inclusivo fundamentado em eleições periódicas não passaria de um esquema governativo de soberania popular duvidosa. Isso porque, além de criar a ilusão da democracia irreal ele deposita nas mãos de uma pequena minoria o poder de governar por todos os indivíduos.

Essas convergências e divergências teóricos revelam esquemas de representação política que possibilitam a inclusão das diversas minorias e também incentivem a existência de mecanismos institucionais e sociais - como uma cultura política e sistemas eleitorais - que favorecem o interesse dos indivíduos pelos assuntos públicos. Embora pensassem o desinteresse cívico e a apatia política sobre óticas diferentes, em um momento encarando como males da própria democracia, e outro como o resultado de uma sociedade avessa a inclusão, esses pensadores guiam nossa atenção para os elementos fundamentais de um governo representativo, popularmente soberano e politicamente igualitário.

Nesse momento podemos vislumbrar os reflexos do pensamento sobre representação política moderna nas experiências contemporâneas de governo representativo. Para tanto, recorreremos a Manin $(1997 ; 1995)$ e sua tentativa de desenvolver um esquema analítico da consolidação da 
Artigo original

Hegemonia - Revista Eletrônica do Programa de Mestrado em Direitos Humanos, Cidadania e Violência/Ciência Política do Centro Universitário Unieuro

ISSN: 1809-1261

UNIEURO, Brasília, número 24, Julho a Dezembro de 2018, pp. 5-23.

democracia representativa ao longo do tempo. Ele nos será para identificar em que medida os pressupostos analisados na seção anterior se refletem nos tipos de governo representativo.

Bernard Manin elaborou uma crítica em torno das deficiências que o desenvolvimento dos diferentes tipos de governo representativo podia oferecer. Sua obra se concentra nas diferenças que os esquemas de representação política causavam aos níveis de identificação entre representantes e representados. No início essa relação era construída pelo parlamento, onde os deputados escolhidos pelo povo sintetizavam os anseios populares. Com o advento da sociedade de massas o regime representativo do tipo parlamentar cedeu lugar ao de partidos que, por seu turno, intensificou os laços de representação entre o eleitor e o eleito, aproximando os cidadãos das agremiações políticas.

No século XX, a consolidação das democracias representativas aconteceu ao mesmo tempo em que a relação de identificação entre representante e representado passava por intensas modificações. Como consequência dos processos de personificação e volatilidade eleitoral (MANIN, 1995), essa relação deixaria de fundamentar-se entre cidadãos e partidos políticos e passaria a acontecer diretamente entre o eleitor e o eleito. Enquanto a primeira transição entre o governo representativoparlamentar e a democracia de partidos foi entendida como um avanço que ampliava a participação cidadã, fortalecendo os laços de identificação entre os eleitores e os representantes, a segunda transição entre a democracia de partidos e a de audiências construiu um ambiente de fraca identificação partidária.

A inclusão de Manin (1995) neste artigo é indispensável pois sua obra aborda alguns princípios que estão presentes em diversas experiências de governo representativo e que por isso favorecerem o nosso entendimento acerca da instrumentalidade e aplicação dos pressupostos teóricos dos pensadores aqui abordados. Os quatro princípios que dão existência aos governos representativos são o resultado do esforço teórico de Manin (ibid.) em capturar as características essenciais que distinguem a representação política nas democracias contemporâneas. Tais princípios são: 1) os indivíduos têm a capacidade de escolher seus representantes em eleições periódicas; 2) os representantes gozam de certo grau de independência de ação frente aos desejos de seus eleitores; 3) os indivíduos gozam de liberdade para manifestar suas ideias sobre assuntos políticos que possam interferir nas futuras eleições; e 4) as 
Artigo original

Hegemonia - Revista Eletrônica do Programa de Mestrado em Direitos Humanos, Cidadania e Violência/Ciência Política do Centro Universitário Unieuro

ISSN: 1809-1261

UNIEURO, Brasília, número 24, Julho a Dezembro de 2018, pp. 5-23.

decisões políticas são tomadas em um ambiente de discussões e debate que possibilitam a livre escolha das melhores opções pelos indivíduos.

Esses princípios permitem que compreendamos como os modelos de representação política das democracias contemporâneas espelham mecanismos institucionais que concedem aos indivíduos a oportunidade de escolher seus governantes por meio de eleições periódicas. Nesse sentido, o caráter da soberania popular se torna um dos objetivos perseguidos pelos modelos contemporâneos de representação política tal como defendiam os autores federalistas, Robert Dahl e Stuart Mill.

Nesse processo de consolidação das democracias representativas exposto por Manin (1995), também verificamos que a igualdade política se tornou um norteador dos sistemas políticos contemporâneos e passou a ser experiência real nas democracias ao redor do mundo. $\mathrm{O}$ voto do cidadão é o elemento que sintetiza o cumprimento da ideia de igualdade política e que aufere aos indivíduos a plataforma básica para a participação nos negócios públicos. Esse ideal foi destaque nas obras de Stuart Mill e Tocqueville, onde, respectivamente, o aprimoramento humano e a os males do individualismo eram prevenidos pela participação dos cidadãos na esfera de deliberação pública.

Os elementos que dão sustentação ao governo de soberania popular e igualdade política discutidos na obra de Dahl (1989) também se fazem presentes nas condições elencados por Manin (1995). Os princípios presentes nos governos de democracia representativa desse autor fornecem as mesmas condições que Dahl (ibid.) elencou para o cumprimento da regra da maioria, para que os indivíduos tenham acesso às informações e para que seja construído um ambiente onde os cidadãos possam tomar as decisões que acham mais adequadas.

\section{Considerações Finais}

Longe de esgotar o tema ao qual pretendeu discutir, nosso esforço se concentrou em destrinchar algumas obras de autores de extrema relevância para a teoria política e achar pontos de convergência, divergência e complementaridade que nos fizesse refletir sobre fundamentos da 
Artigo original

Hegemonia - Revista Eletrônica do Programa de Mestrado em Direitos Humanos, Cidadania e Violência/Ciência Política do Centro Universitário Unieuro

ISSN: 1809-1261

UNIEURO, Brasília, número 24, Julho a Dezembro de 2018, pp. 5-23.

representação política. Com base nos pressupostos centrais das obras de Stuart Mill, Alexis de Tocqueville, Robert Dahl e dos artigos federalistas pudemos refletir acerca da contribuição de textos canônicos da teoria política para o pensamento moderno de representação política. A reforma da engenharia institucional norte-americana com intuito de capacitar o sistema político para responder as necessidades que os esquemas de soberania popular e igualdade política requeriam foi o ponto de partida. De Robert Dahl apreendemos a importância das eleições como instrumento que permite a inclusão das minorias e que favorecem a pluralidade de interesses. Elementos estes que são tão caros as democracia de governo representativo.

As obras de Mill e Tocqueville despertam a necessidade da instauração de condições políticas e sociais que favorecem o interesse cívico dos cidadãos. Por fim, as obras de Bernard Manin nos servem como modelo comparativo. Nelas podemos vislumbrar os reflexos do pensamento moderno sobre representação política nas experiências reais de governos representativos.

Referencias Bibliográficas

DAHL, Robert. [1956] Um Prefacio a teoria democrática. Trad. De Ruy Jungmann. Rio de janirro: Zahar, 1989.

JASMIM, Marcelo Gantus. Alexis de Tocqueville: a historiografia como ciência da política. Belo Horizonte: Editora UFMG, 2005.

MADISON, J.; HAMILTON, A.; JAY, J. [1788] Os Artigos Federalistas: 1787 -1788. Trad de Maria Luiza A. Borges. Rio de Janeiro: Nova Fronteira, 1993.

MANIN, Bernard. The Principles of representative governenment. Cambridg University Press, 1997.

MANIN, Bernard. As metamorfoses do governo representativo. Trad. De Vera Pereira. Revista Brasileira de Ciências Sociais, n. 29,. São Paulo: ANPOCS, 1995.

PATEMAN, Carole. [1970]. Participação e Teoria Democrática. Trad. De Luiz Paulo Rounet. Rio de Janeiro: Paz e Terra, 1992. 
Artigo original

Hegemonia - Revista Eletrônica do Programa de Mestrado em Direitos Humanos, Cidadania e Violência/Ciência Política do Centro Universitário Unieuro

ISSN: 1809-1261

UNIEURO, Brasília, número 24, Julho a Dezembro de 2018, pp. 5-23.

TOCQUEVILLE, Alexis de. [1835]. A democracia na America. Trad. De Neil Ribeiro da Silva. São Paulo: Edusp, 1977. 